\title{
A study on the improvement of portable fuel cell fan
}

\author{
Joo-Han Kim ${ }^{1}$, Jung-Moo Seo ${ }^{1}$, In Sung Chung ${ }^{1}$, Nahm-keon Hur ${ }^{2}$ \\ ${ }^{1}$ Korea Electronics Technology Institute (KETI) \\ 203-103 B/D 192 Yakdae-Dong, Wonmi-Gu \\ Puchon-Si, Kyunggi-Do, 420-140, Korea \\ Phone number: +82-32-621-2849, Fax number: +82-32-621-2855, e-mail address: kimjh@keti.re.kr \\ ${ }^{2}$ Sogang University, Department Of Mechanical Engineering \\ Sinsoo 1, Mapo, Seoul, 121-742, Korea
}

\begin{abstract}
.
Recently, due to the exhaustion of fossil fuel, pollution of air, and demand for capacity increase of power system, new generating technologies using various energy sources, for instance wind, water, geothermal, fuel cell, have been developed. Among them, fuel cell system which generates electric energy from chemical reaction of hydrogen and oxygen is considered one of the promising. This study is thing to develop small size light weight high effectiveness portable fuel cell Air Fan module. We achieved flow analysis about air Fan and presented various design data. And we wish to accomplish fan performance elevation and commercialization through this.
\end{abstract}

\section{Key words}

Fuel cell, Fan, Blade, CFD

\section{Introduction}

Recently, due to the exhaustion of fossil fuel, pollution of air, and demand for capacity increase of power system, new generating technologies using various energy sources, for instance wind, water, geothermal, fuel cell, have been developed. Among them, fuel cell system which generates electric energy from chemical reaction of hydrogen and oxygen is considered one of the promising alternatives due to aspects of environment conservation as well as high efficiency. Fuel cell systems consist of fuel cell stack, air management system, and power conditioning system. Air management systems composed of pump, fan, compressor, and blower determine output performance of overall system on the preferential basis. Besides, the proper matching of a fan's speed/torque curve to aerodynamic output is especially important in increasing efficiency thereby reducing its demand on a fuel cell system.

This study is thing to develop small size light weight high effectiveness portable fuel cell Air Fan module. We achieved flow analysis about air Fan and presented various design data. And we wish to accomplish fan performance elevation and commercialization through this.

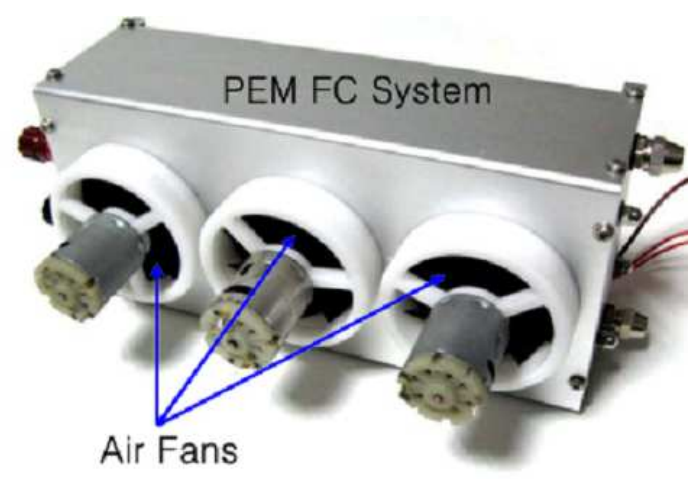

Fig. 1 Portable PEM FC System

And when fan rotate, we analyzed flow by using analysis lattice method. Thus, an established analysis technology is applied in Fan design and examined effect of Fan blade shape, number etc. It is that cause big effect in performance elevation of system and stability security by study interrelation with pressure using the result.

When we analyzed flow, and analyzed whole system that do not analyze fan simply. And we presented wide analysis result that can be applied in design by considering various fan shape and outside shape etc.

\section{Air Fan flow analysis theory}

Navier-Stokes equation and k-e 2 equations turbulent flow model of moved object. We used ALE (Arbitrary Lagrangian Eulerian) method to analyze object surrounding fluid flow that move with fan using CFD. This method calculates that do to reflect transfer of lattice applying to Navier-Stokes equation about fixing coordinate system.

Here, $u$ is speed of incompressible fluid, $v$ is movement speed of lattice. 
$\frac{\partial\left(u_{i}-v_{i}\right)}{\partial x_{i}}=0$

$$
\frac{\partial \rho u_{i}}{\partial t}+\frac{\partial\left(u_{j}-v_{j}\right) \rho u_{i}}{\partial x_{j}}=\frac{\partial p}{\partial x_{i}}+\frac{\partial}{\partial x_{j}} \mu \frac{\partial u_{i}}{\partial x_{j}}
$$

It is that need to introduce turbulent flow model to analyze turbulent flow.

Reynolds stress $\left(-\rho \overline{u_{i} u_{j}}\right)$ that is turbulent flow stress in viscosity clause if arrange Navier-Stokes equation dividing the speed that change according to time of turbulent flow into the average (time average) speed and change minute (fluctuating component) time is occurred and has 6 unknown terms. Also, have a lot of numbers of unknown term by Reynolds stress than number of equation even if motive transport equation to solve this Reynolds stress. Therefore, utilize turbulent flow model because produce closure problem that cannot close equation. We use that factor of stress and speed by viscosity is in proportion.

$-\rho \overline{u_{i} u_{j}}=\mu_{t}\left(\frac{\partial u_{i}}{\partial x_{j}}+\frac{\partial u_{j}}{\partial x_{i}}\right)-\frac{2}{3} \rho k \delta_{i j}$

$k=\frac{1}{2}\left(\overline{u_{1}^{2}}+\overline{u_{2}^{2}}+\overline{u_{3}^{2}}\right) \quad \mu_{t}=C_{t} \rho \frac{k^{2}}{\varepsilon}$

We can define using turbulence energy $\mathrm{k}$ and viscosity dissipation rate $\varepsilon$ and comparison coefficient called turbulent eddy viscosity ${ }^{\mu_{t}}$ if suppose with upside.

It is turbulent flow model that using equation or solving briefly from experience formula. Usually, it is known that method that substitute this $\mathrm{k}$ and $\varepsilon$ to transport equation and drains 2 equations is $k-\varepsilon$ turbulent flow model. RANS (Reynolds Average Navier-Stokes) method uses much in industrial field because convergence and computing time are the best. This transport equation of $\mathrm{k}$ $\varepsilon$ turbulent flow model is as following.

$\frac{\partial \rho k}{\partial t}+\frac{\partial\left(u_{i}-v_{i}\right) \rho k}{\partial x_{i}}=\frac{\partial}{\partial x_{i}}\left(\frac{\mu_{t}}{\sigma_{k}} \frac{\partial k}{\partial x_{i}}\right)+G_{S}+G_{T}-\rho \varepsilon$

$\frac{\partial \rho \varepsilon}{\partial t}+\frac{\partial\left(u_{i}-v_{i}\right) \rho \varepsilon}{\partial x_{i}}=\frac{\partial}{\partial x_{i}}\left(\frac{\mu_{t}}{\sigma_{\phi}} \frac{\partial \varepsilon}{\partial x_{i}}\right)+C_{1} \frac{\varepsilon}{k}\left(G_{s}+G_{T}\right)\left(1+C_{3} R_{f}\right)-C_{2} \frac{\rho \varepsilon^{2}}{k}$

$G_{S}=\mu_{t}\left(\frac{\partial u_{i}}{\partial x_{j}}+\frac{\partial u_{j}}{\partial x_{i}}\right) \frac{\partial u_{i}}{\partial x_{j}} \quad G_{T}=g_{i} \beta \mu_{t} \frac{\mu_{t}}{\sigma_{t}} \frac{\partial T}{\partial x_{i}}$

$R_{f}=-\frac{G_{T}}{G_{S}+G_{T}}$

Unsteady state flow analysis method of fan by using CFD

In this study, we achieved computing flow analysis to use universal design tool. This analysis tool can use hybrid grid, and Navier-Stokes equation did discetization by node based FVM about space. It is used 1st order Implicit method about time, and apply 2nd order MUSCL method about convection term. Also, in this study, we gave special volume in fan blade surrounding, and did interpolation every intervals of time that interface of rotating area and stationary area, and used sliding mesh function that is method that describe rotation of fan.

\section{Flow analysis results}

CAE analysis modelling

And we get fan blade scan data by using scan equipment. Fan blade numbers are $10 \mathrm{EA}$ that see in picture of under. We run modelling motor of actual size because Fan blade and had combined motor can influence in backwash.
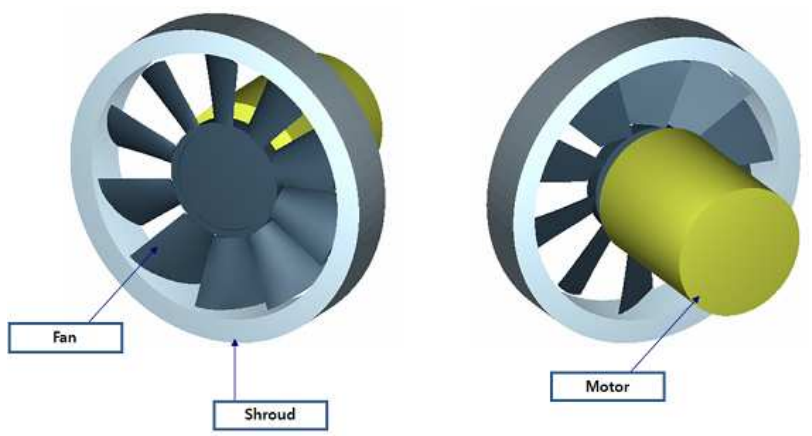

Fig. 2 Air fan modelling

Analysis meshing

We created mesh of Fan surrounding densely to improve accuracy of flow analysis.

Surface: $0.35 \mathrm{~mm}$, Prism layer: $0.09 \mathrm{~mm}$ ( 2 layer) The numbers of meshing element: 10,924,754 Elements $(2,326,960$ nodes $)$

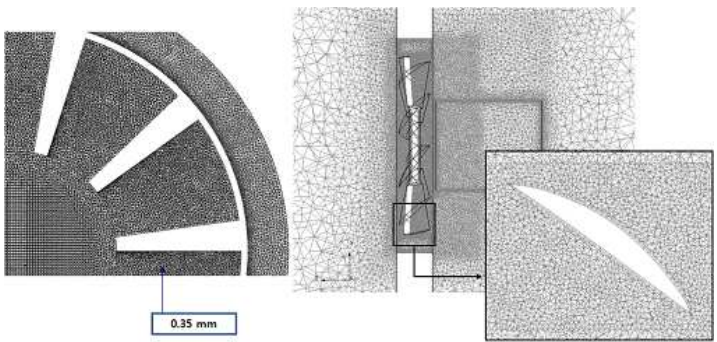

Fig. 3 Meshing elements of fan blade

Boundary condition

The analysis of air fan blade used Steady ALE (Arbitrary Lagrangian Eulerian) method. We modeled greatly enough to size of calculation area is not influenced Fan flow. This is to avoid that outside boundary condition interferes in main flow

- Steady ALE method

- Rotating speed: 7,000 rpm

- Pressure In/Outlet: Atmospheric pressure 


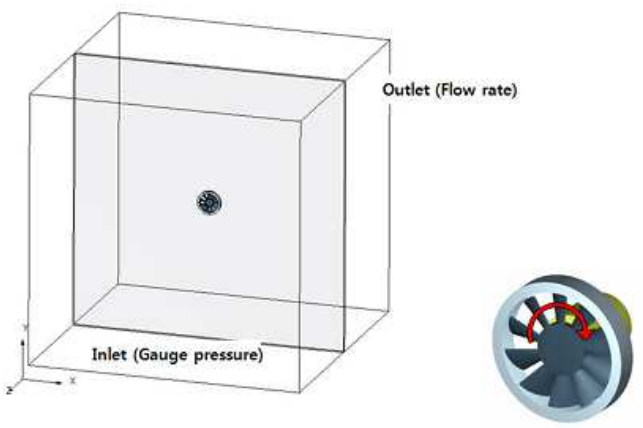

Analysis models

Analysis model achieved analysis about 2 models in this study. We carried out that existing Fan blade shape and

(Case 1), and making model (Case 2) that did $0.2 \mathrm{~mm}$ extrude to normal direction extracting suction side surface shape of existing fan blade.
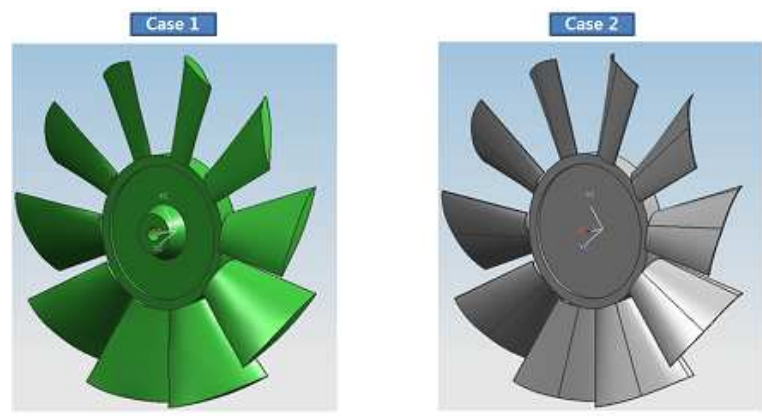

Fig. 4 Analysis models (Case 1,2)

Analysis result

As see in result of under, the efficiency of air fan Case 2 more felled off than the efficiency of existing air fan case 1. This informs that it is difficult to improve performance of fan to simplicity blade Shape change. We confirmed that is in both Case 1 and 2 optimum design area in Cordier diagram chart.
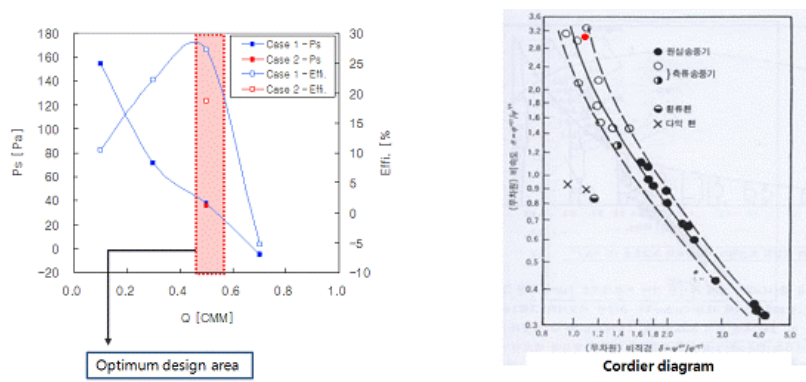

Fig. 5 P-Q Curve of case1, 2/ Cordier diagram

Table I. - Analysis result sheet

\begin{tabular}{|c|c|c|c|c|c|c|c|}
\hline NO & $\begin{array}{c}\mathbf{Q} \\
(\mathrm{CMM})\end{array}$ & $\begin{array}{c}\mathrm{H} \\
(\mathbf{m m A q})\end{array}$ & $\begin{array}{c}\mathrm{D} \\
(\mathbf{m m})\end{array}$ & $\begin{array}{c}\mathbf{P w} \\
(\mathbf{w})\end{array}$ & $\begin{array}{c}\mathbf{Q} \\
(\mathrm{CMS})\end{array}$ & $\begin{array}{c}\mathrm{H} \\
(\mathrm{Pa})\end{array}$ & $\begin{array}{c}\mathbf{w} \\
(\mathbf{r a d} / \mathbf{s})\end{array}$ \\
\hline $\begin{array}{c}\text { Case } \\
\mathbf{1}\end{array}$ & 0.50 & 3.85 & 55 & 1,160 & 0.008 & 37.7 & 733 \\
\hline $\begin{array}{c}\text { Case } \\
\mathbf{2}\end{array}$ & 0.50 & 3.85 & 55 & 1,607 & 0.008 & 36.0 & 733 \\
\hline
\end{tabular}

\begin{tabular}{|c|c|c|c|c|c|c|c|}
\hline NO & $\begin{array}{c}\text { Pair } \\
(\mathbf{w})\end{array}$ & $\underline{\underline{\text { Effi }}}$ & $\begin{array}{c}\text { Capacity } \\
\text { coeffi }\end{array}$ & $\begin{array}{c}\text { Head } \\
\text { coeffi }\end{array}$ & $\begin{array}{c}\text { Specific } \\
\text { speeds }\end{array}$ & $\begin{array}{c}\text { Specific } \\
\text { dia }\end{array}$ & $\begin{array}{c}\text { N } \\
(\mathrm{RPM})\end{array}$ \\
\hline $\begin{array}{c}\text { Case } \\
\mathbf{1}\end{array}$ & 0.314 & $\underline{27.1}$ & 0.174 & 0.077 & 2.856 & 1.2625 & 7,000 \\
\hline $\begin{array}{c}\text { Case } \\
\mathbf{2}\end{array}$ & 0.300 & $\underline{18.7}$ & 0.174 & 0.077 & 2.856 & 1.2625 & 7,000 \\
\hline
\end{tabular}

The pictures of under are pictures that analyze pressure distribution by each volume flow rate of air fan. We could know in high-pressure condition that pressure of fan- pressure side is high, and in high-flow rate condition that pressure of fan leading edge is high. And we could know in best efficiency point $(0.5 \mathrm{CMMs})$ condition that pressure distribution of fan-front and fan-back is uniform relatively.

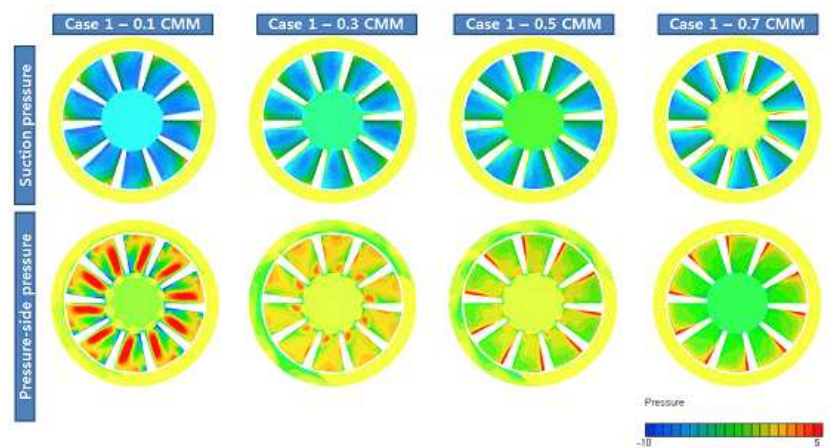

Fig. 6 Pressure distribution by each volume flow rate of air fan

The pictures of under are pictures that analyze pressure distribution of air fan section and relative speed. We could know in high-pressure condition that pressure of fan- pressure side is high, and in high-flow rate condition that pressure of fan suction side is lower, and that occurrence of leading edge separation grows bigger in the characteristic amount.

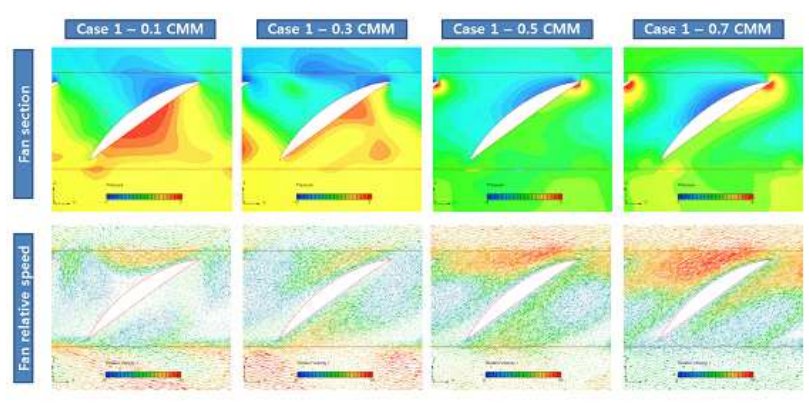

Fig. 6 Air Fan section flow analysis

The pictures of under are pictures that compare flow analysis result of Case 2 with Case 1 . We could know in case 2 that pressure distribution of fan-pressure side is poor. This means that efficiency becomes low due to consume more driving torque in uniformity flow performance. And in the case of Case 2, due to pressure difference of Suction side and Pressure side is bigger, torque grows bigger, and efficiency is poor. 

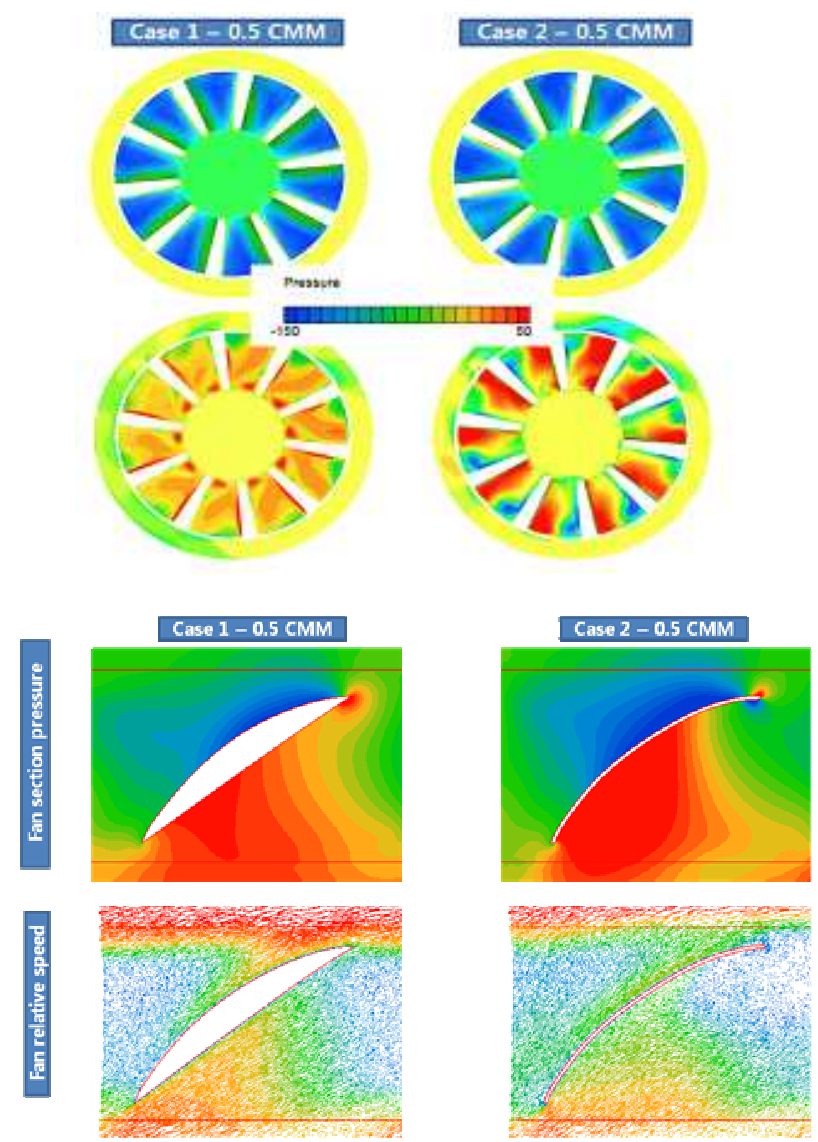

Telecommunications Energy Special, 2000. TELESCON. The Third International Conference on

Fig. 8 comparison flow analysis result of Case 2 with Case 1

\section{Conclusion}

In this study, Air Fan blade used to existing portable fuel cell analyzed special quality about efficiency and pressure through flow analysis. And we modelled new Fan blade through thickness shape change of Fan blade and did flow analysis. As see in result, we knew that it is difficult to improve performance of fan to simplicity blade Shape change. In future, we will achieve Fan blade 3D shape change so that raise efficiency of fuel cell Air Fan. And we improve Fan efficiency through modelling and flow analysis in analysis level. We are going to progress experimental test to prove this..

\section{References}

[1] N. Kato and K. Kurozumi, "Hybrid power supply system composed of photovoltaic and fuel-cell systems,"in Proc. INTELEC'01, Oct. 2001, pp. 631-635.

[2] M. N. Eskander and T. F. El-Shatter, "Energy flow and management of a hybrid wind/PV/fuel cell generation

system," in Proc. IEEE PESC'02, Jun. 2002, pp. 347-353

[3] Ellis, M.W, Von Spakovsky, "Fuel cell systems: efficient, flexible energy conversion for the 21 st century" Proceedings of the IEEE, Volume 89, Issue 12, Dec. 2001

[4] Ternan, M, "The potential of direct hydrocarbon fuel cells for improving energy efficiency", EIC Climate Change Technology, 2006 IEEE, 2006 Page(s): 1 - 4

[5] Kato, N.; Murao, T.; Fujii, K.; Aoiki, T.; Muroyama, S, "1 $\mathrm{kW}$ portable fuel cell system based on PEFCs", 